\title{
ANALISIS KETIDAK SEIMBANGAN BEBAN TRANSFORMATOR DAYA 30 MVA 70/20 KV PT.PLN (Persero) ULTG LAHAT
}

\author{
SURYA DARMA \\ Dosen Tetap Yayasan Pada Program Studi Teknik Elektro \\ Fakultas Teknik Universitas Palembang e-mail :Suryadarma.stmt @ gmai.com
}

\begin{abstract}
ABSTRAK
Penyediaan energi listrik yang stabil dan kontinu merupakan syarat mutlak yang harus dipenuhi dalam memenuhi kebutuhan energi listrik. Namun dalam memenuhi kebutuhan tenaga listrik tersebut terjadi pembagian beban - beban yang tidak merata sehingga menimbulkan suatu ketidakseimbangan beban pada transformator yang dampaknya dapat merugikan PLN. Transformator adalah suatu alat untuk memindahkan daya listrik arus bolak - balik dari suatu rangkaian ke rangkaian lainnya. Sifat terpenting dari pembebanan yang seimbang adalah jumlah phasor dari ketiga tegangan adalah sama dengan nol, begitupula dengan jumlah phasor dari arus pada ketiga fase juga sama dengan nol. Beberapa aspek yang di perlukan untuk manganalisa ketidak seimbangan beban pada transformator daya tersebut antara lain diperlukan penggukuran setiap jamnya. Ketidak seimbangan beban pada transformator daya selalu terjadi dan penyebab ketidak seimbangan tersebut adalah pada beban-beban pada pelanggan jaringan tegangan rendah. Akibat ketidak seimbangan beban tersebut timbullah arus di netral trafo. Arus yang mengalir di netral trafo ini menyebabkan terjadinya losses (rugi-rugi), yaitu losses akibat adanya arus netral pada penghantar netral trafo dan losses akibat arus netral yang mengalir ke tanah. Setelah dianalisis, diperoleh bahwa bila terjadi ketidak seimbangan beban yang besar, maka arus netral yang muncul juga besar, dan losses akibat arus netral yang mengalir ke tanah semakin besar pula.
\end{abstract}

Kata kunci : Ketidak seimbangan Beban,Taransformator, arus netral, losses.

\section{PENDAHULUAN}

\subsection{Latar Belakang [1].[2].[3].}

Di masa sekarang kebutuhan listrik semakin meningkat sejalan dengan berkembangnya teknologi.Perkembangan yang pesat ini harus diikuti dengan keandalan energi listrik yang dihasilkan. Saat ini tenaga listrik merupakan kebutuhan yang utama, baik untuk kebutuhan sehari-hari maupun untuk kebutuhan industri.Penyediaan energi listrik yang stabil dan kontinu merupakan syarat mutlak yang harus dipenuhi dalam memenuhi kebutuhan energi listrik. Perkembangan pembangunan di segala bidang menuntut PLN agar dapat menyediakan tenaga listrik sesuai dengan kebutuhan konsumen. Namun dalam memenuhi kebutuhan tenaga listrik tersebut terjadi pembagian beban-beban yang tidak merata sehingga menimbulkan suatu ketidak seimbangan beban pada transformator

\subsection{Tujuan Penelitian}

Adapun tujuan dalam penulitian ini Mengidentifikasi ketidak seimbangan beban yang terjadi,Melakukan kajian penyebab ketidak seimbangan beban pada transformator daya,Mencari solusi yang akandigunakan untuk ketidak seimbangan beban pada transformator daya.

\subsection{Manfaat Penelitian.}

Dengan dilakukan Penelitian ini,maka diharapkan pihak perusahaan yaitu PT.PLN (Persero) ULTG Lahat dapat mengatasi ketidak seimbangan beban yang terjadi serta memberikan solusi yang terbaik.

Analisis Ketidak Seimbangan Beban Transformator Daya 30 MVA 70/20 KV

PT.PLN (Persero) ULTG Lahat

(Surya Darma) 


\subsection{Ruang Lingkup Penelitian}

Penelitian yang dilakukan adalah menganalisis ketidak seimbangan beban terhadap transformator daya 30 MVA 70/20 KV PT.PLN (Persero) ULTG Lahat.

\section{Tinjauan Pustaka.}

\subsection{Transformator Daya.[3].[6]}

Transformator merupakan suatu alat magnetoeliktrik yang sederhana, andal, dan efisien untuk mengubah tegangan arus bolak - balik dari satu tingkat ketingkat yang lain. Pada umumnya transformator terdiri atas sebuah inti, yang terbuat dari besi berlapis, dan duah buah kumparan, yaitu kumparan primer, dan kumparan skunder. Secara umum dapat dibedakan dua jenis transformator menurut kontruksinya, yaitu tipe inti, dan tipe cangkang. Pada tipe inti terdapat dua kaki, dan masing masing kaki dibelit oleh kedua kumparan. Sedangkang tipe cangkang mempunyai tiga kaki, dan hanyah kaki yang tengah - tengah yang di belit oleh kumparan.

Transformator adalah suatu alat untuk memindahkan daya listrik arus bolak - balik dari suatu rangkaian ke rangkaian lainnya. Trasnformator terdiri dari tiga komponen pokok yaitu:

- Kumparan pertama ( Primer ) yang bertindak sebagai input

- Kumparan kedua ( Skunder ) yang bertindak sebagai output

- Inti besi yang berfungsi untuk memperkuat medan magnet yang di hasilkan

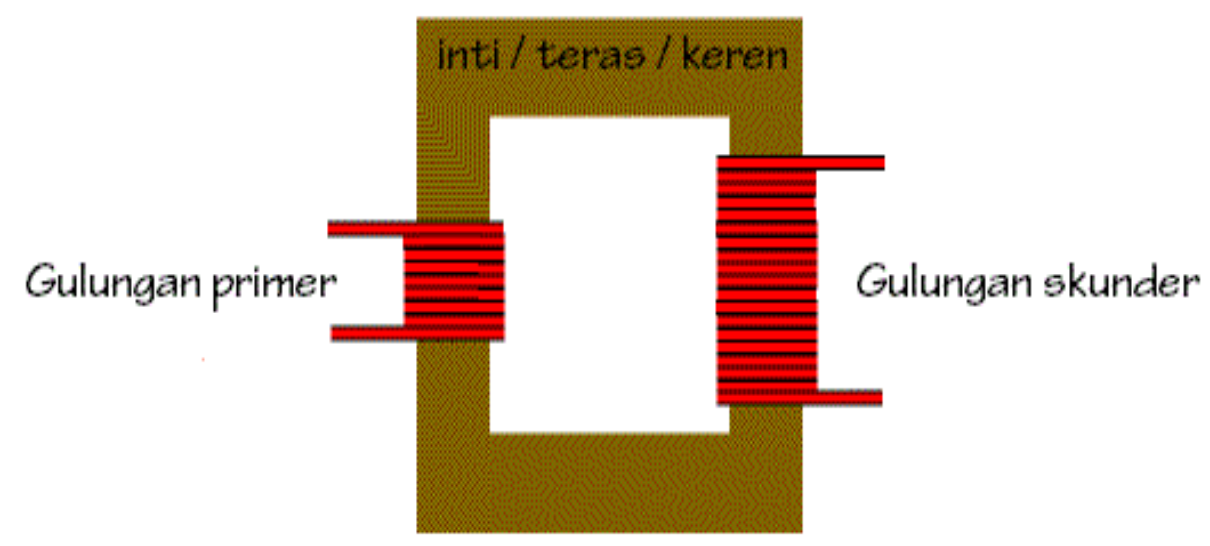

Gambar.2.1.Bagian-Bagian Transformator

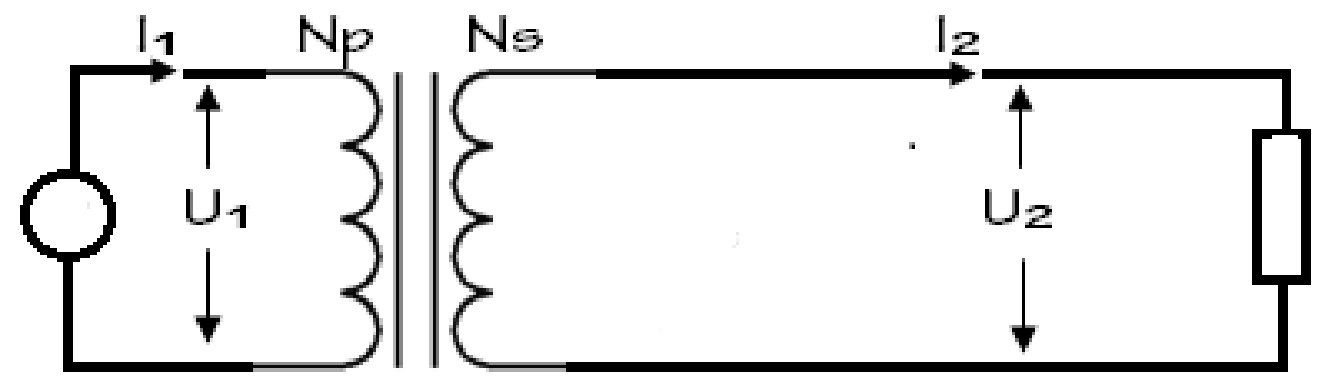

Gambar 2.2 bagan transformator

Dimana

Analisis Ketidak Seimbangan Beban Transformator Daya 30 MVA 70/20 KV

PT.PLN (Persero) ULTG Lahat

(Surya Darma) 
$\mathbf{U}_{1}$ : Tegangan primer

$\mathbf{U}_{2}$ : Tegangan skunder

$\mathbf{I}_{1}$ : Arus primer

$\mathbf{I}_{2}$ : Arus skunder

Np: Jumlah lilitan kumparan primer

Ns : jumlah lilitan kumparan skunder

\section{2,1. Prinsip Kerja Transformator.[3].[6]}

Apabila kumparan primer di hubungkan dengan tegangan sumbaer maka akan menggalir arus bolak - balik $\left(\mathrm{I}_{1}\right)$ pada kumparan tersebut. Oleh karena kumparan mempunyai inti, arus $\left(\mathrm{I}_{1}\right)$ menimbulkan fluks magnit yang juga berubah - ubah pada intinya. Akibat adanya fluks magnit yang berubah - ubah, pada kumparan primer akan timbul GGL induksi $\left(\mathrm{e}_{\mathrm{p}}\right)$.

Besarnya GGL induksi pada kumparan primer adalah:

$e_{p}=-N p \frac{d \emptyset}{d t}$ volt

Dimana : $\quad e_{\mathrm{p}} \quad$ : GGL induksi pada kumparan primer

$\mathrm{Np} \quad$ : jumlah lilitan kumparan primer

$\mathrm{D} \emptyset \quad$ : perubahan garis - garis gaya magnet dalam satuan weber

Dt : perubahan waktu dalam satuan detik

Fluks magnit yang menginduksikan GGL induksi $\left(\mathrm{e}_{\mathrm{p}}\right)$ juga dialami oleh kumparan skunder karena merupakan fluks bersama ( mutual fluks ). Dengan demikian fluks tersebut menginduksikan GGL induksi es pada kumparan sekunder.

Besarnya GGL induksi pada kumparan sekunder adalah:

$\mathrm{e}_{\mathrm{s}}=-\mathrm{Ns} \frac{\mathrm{d} \emptyset}{\mathrm{dt}}$ volt

Dimana : $\mathrm{N}_{\mathrm{S}}$ : jumlah lilitan kumparan sekunder.

Dari persamaan (1) dan (2) didapatkan perbandingan lilitan berdasarkan perbandingan GGL induksinya

\subsection{Transformator Tiga Fasa.[3].[6].}

Transformator tiga fasa dapat disusun dari tiga buah transformator satu fasa. Akan tetapi biasanya transformator tiga fasa terdiri dari tiga buah transformator satu fasa yang di fasang pada 1 inti.

Pada transformator tiga fasa terdapat 3 buah kumparan primer dan kumparan sekunder. Dari ketiga kumparan ( primer/sekunder) dapat di buat hubungan bintang maupun hubungan segitiga.

Analisis Ketidak Seimbangan Beban Transformator Daya 30 MVA 70/20 KV

PT.PLN (Persero) ULTG Lahat

(Surya Darma) 


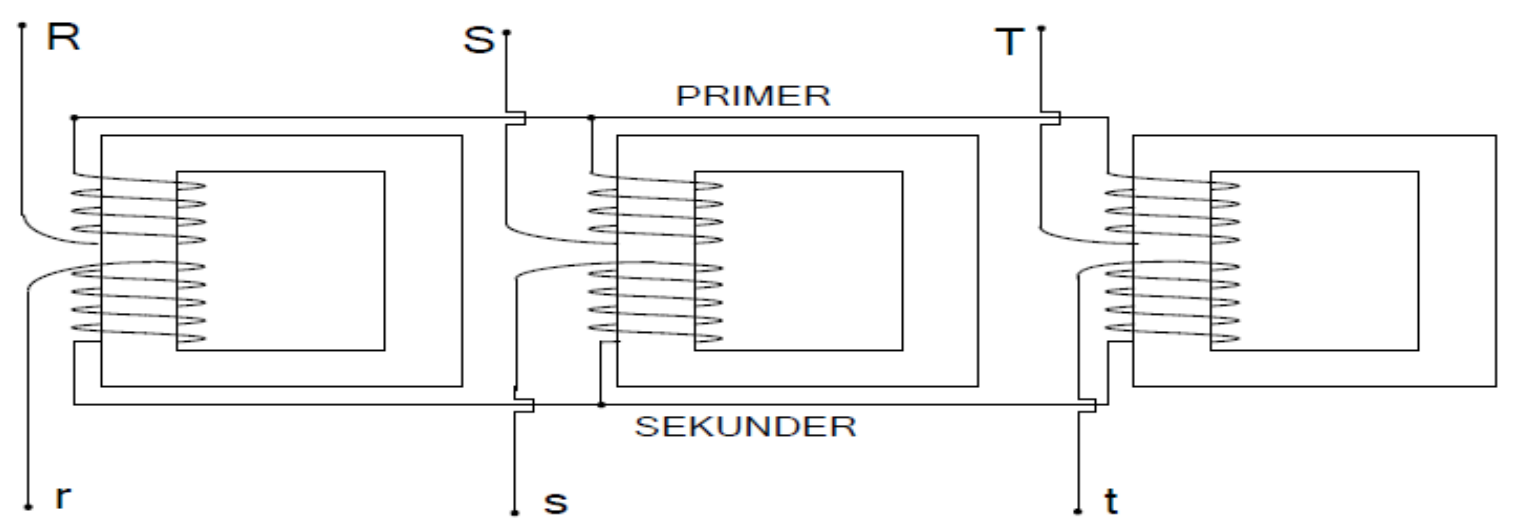

Gambar. 2.10. Transformator 3 fase yang disusun dari 3 buah transformator 1 fasa

\section{Hubungan Transformator Tiga Fhasa}

Secara umum ada 3 macam jenis hubungan pada transformator tiga phasa yaitu :

1. Hubungan Bintang (Y)

2. Hubungan segi 3 delta $(\Delta)$

3. Hubungan Zigzag

\section{Hubungan bintang (Y).[9].}

Hubungan bintang ialah hubungan transformator tiga fasa, dimana ujung-ujung awal atau akhir lilitan disatukan. Titik dimana tempat penyatuan dari ujung-ujung lilitan merupakan titik netral. Arus transformator tiga phasa dengan kumparan yang dihubungkan bintang yaitu; IA, IB, IC masingmasing berbeda $120^{\circ}$.

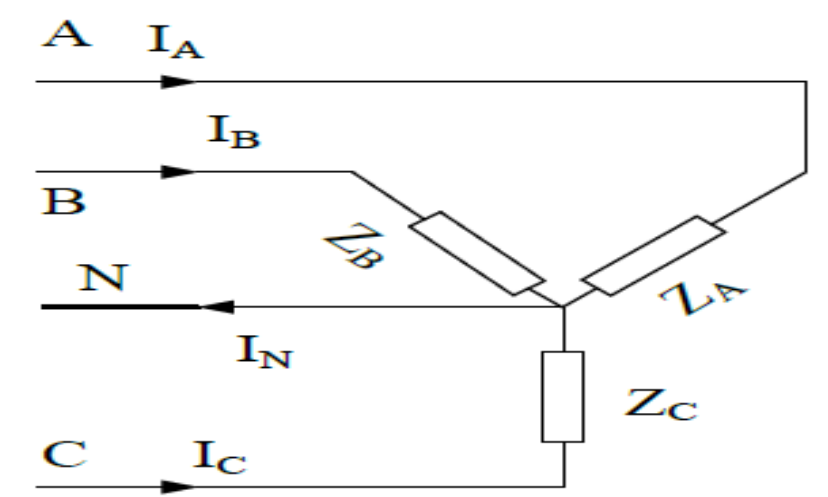

Gambar 2.11. Transformator 3 fasa hubungan bintang

Dari gambar diatas diperoleh bahwa :

$$
\begin{array}{ll}
\mathrm{I}_{\mathrm{A}} & =\mathrm{I}_{\mathrm{B}}=\mathrm{I}_{\mathrm{C}}=\mathrm{I}_{\mathrm{L}} \ldots \ldots \ldots \\
\mathrm{I}_{\mathrm{L}} & =\mathrm{Iph} \ldots \ldots \ldots \ldots \ldots \\
\mathrm{V}_{\mathrm{AB}} & =\mathrm{V}_{\mathrm{BC}}=\mathrm{V}_{\mathrm{CA}}=\mathrm{V}_{\mathrm{L}-\mathrm{L}} \\
\mathrm{V}_{\mathrm{L}-\mathrm{L}} & =\sqrt{3} \mathrm{~V} \mathrm{Vh} . \ldots \ldots \ldots \ldots
\end{array}
$$

Dimana: $\quad \mathrm{V}_{\mathrm{L}-\mathrm{L}}=$ tegangan line to line (Volt)

Analisis Ketidak Seimbangan Beban Transformator Daya 30 MVA 70/20 KV

PT.PLN (Persero) ULTG Lahat

(Surya Darma) 


$$
\begin{array}{ll}
\mathrm{Vph} & =\text { tegangan phasa }(\text { Volt }) \\
\mathrm{Iph} & =\operatorname{arus} \text { phasa }(\text { Ampere }) \\
\mathrm{IL} & =\text { arus line (Ampere) }
\end{array}
$$

\section{Hubungan Segitiga/ Delta $(\Delta)[9]$.}

Hubungan segitiga adalah suatu hubungan transformator tiga fasa, dimana cara penyambungannya ialah ujung akhir lilitan fasa pertama disambung dengan ujung mula lilitan fasa kedua, akhir fasa kedua dengan ujung mula fasa ketiga dan akhir fasa ketiga dengan ujung mula fasa pertama. Tegangan transformator tiga phasa dengan kumparan yang dihubungkan segitiga yaitu; VA, $\mathrm{VB}, \mathrm{VC}$ masing-masing berbeda $120^{\circ}$.

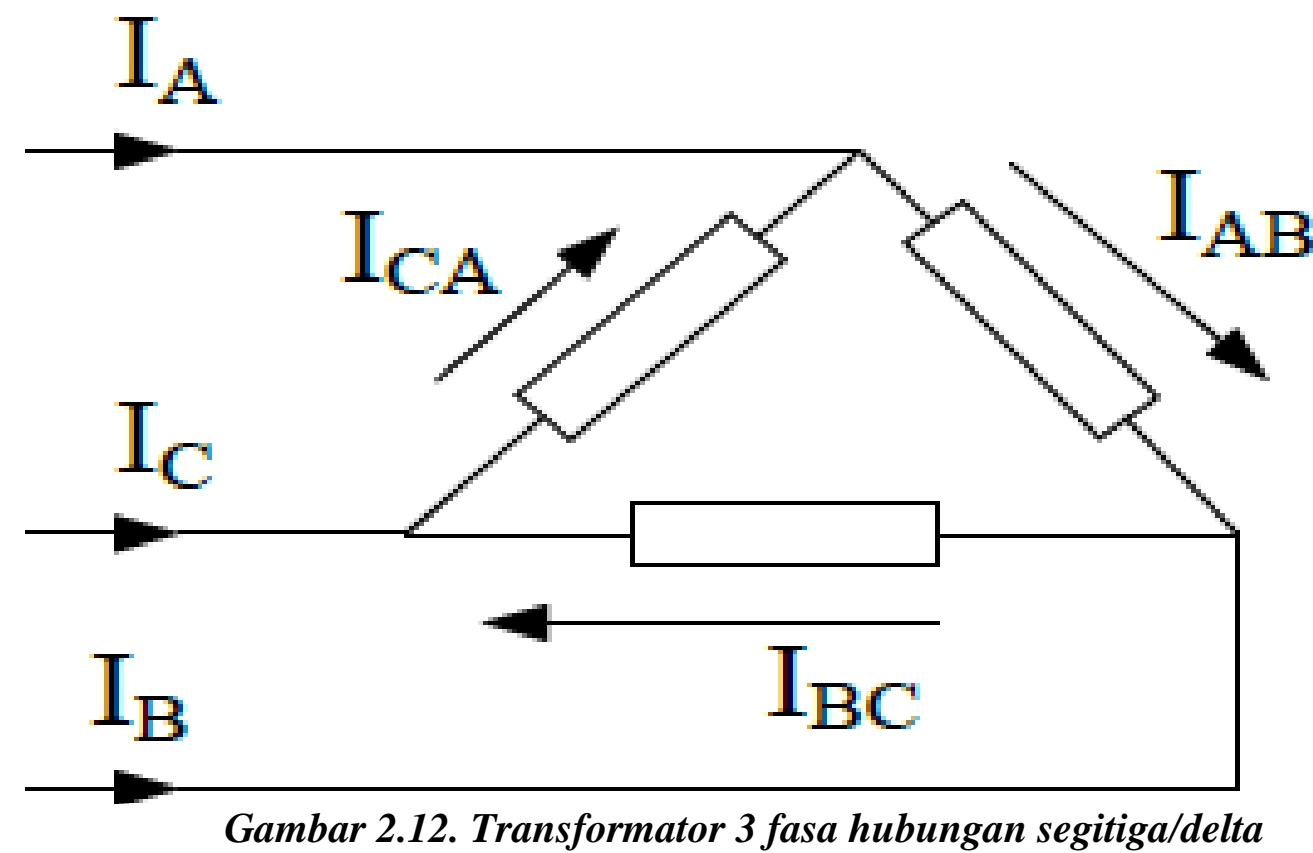

Dari gambar diatas diperoleh bahwa :

$$
\begin{array}{ll}
\mathrm{I}_{\mathrm{A}} & =\mathrm{I}_{\mathrm{B}}=\mathrm{I}_{\mathrm{C}}=\mathrm{I}_{\mathrm{L}} \ldots \ldots \ldots \\
\mathrm{I}_{\mathrm{L}} & =\sqrt{3} \mathrm{Iph} \ldots \ldots \ldots \ldots \ldots \\
\mathrm{V}_{\mathrm{AB}} & =\mathrm{V}_{\mathrm{BC}}=\mathrm{V}_{\mathrm{CA}}=\mathrm{V}_{\mathrm{L}-\mathrm{L}} \\
\mathrm{V}_{\mathrm{L}-\mathrm{L}} & =\mathrm{Vph} \ldots \ldots \ldots \ldots \ldots \ldots \ldots \ldots \ldots \ldots
\end{array}
$$

Dimana : VL-L $=$ tegangan line to line $($ Volt $)$

$$
\begin{aligned}
\mathrm{Vph} & =\text { tegangan phasa }(\text { Volt }) \\
\mathrm{IL} & =\text { arus line }(\text { Ampere }) \\
\mathrm{Iph} & =\text { arus phasa (Ampere) }
\end{aligned}
$$

\section{Hubungan Zigzag}

Transformator $z i g-z a g$ merupakan transformator dengan tujuan khusus. Salah satu aplikasinya adalah menyediakan titik netral untuk sistem listrik yang tidak memiliki titik netral. Pada 
transformator zig-zag masing-masing lilitan tiga fasa dibagi menjadi dua bagian dan masing-masing dihubungkan pada kaki yang berlainan.
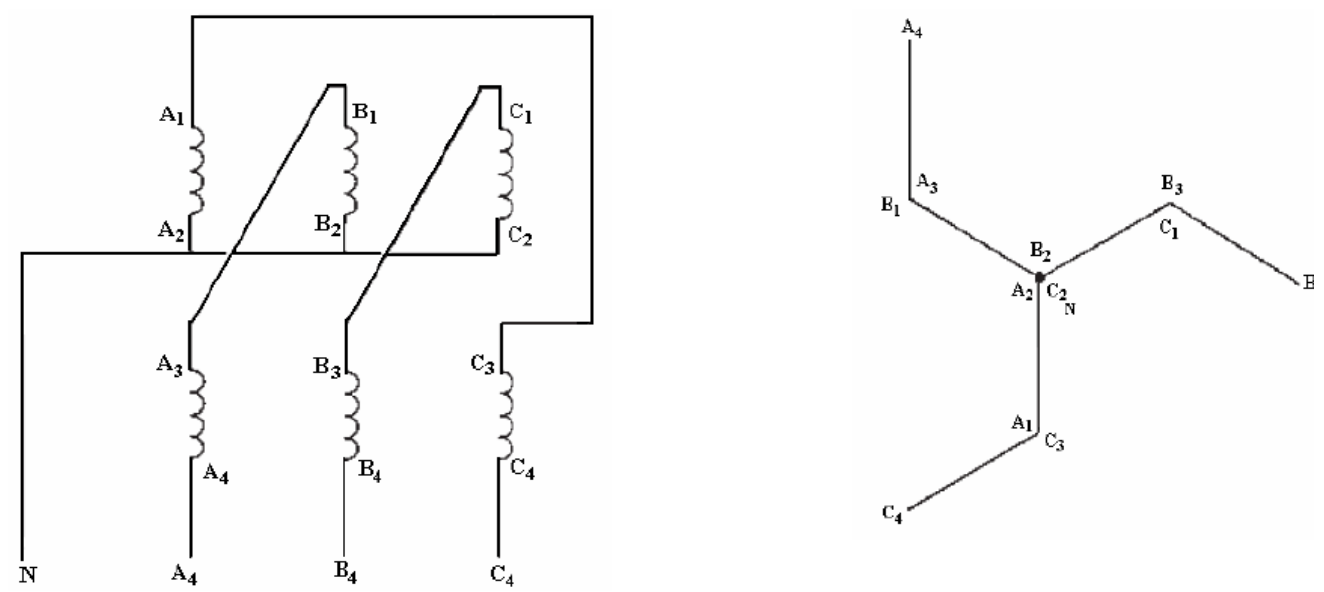

Gambar. 2.13. Transformator 3 fasa hubungan zig - zag

\section{2,4, Daya Sistem 3 Fase pada Beban Yang Tidak Seimbang. [4].[5]}

Sifat terpenting dari pembebanan yang seimbang adalah jumlah phasor dari ketiga tegangan adalah sama dengan nol, begitupula dengan jumlah phasor dari arus pada ketiga fase juga sama dengan nol. Jika impedansi beban dari ketiga fase tidak sama, maka jumlah phasor dan arus netralnya (In) tidak sama dengan nol dan beban dikatakan tidak seimbang. Ketidakseimbangan beban ini dapat saja terjadi karena hubung singkat atau hubung terbuka pada beban.

Dalam sistem 3 fase ada 2 jenis ketidakseimbangan, yaitu:

1. Ketidakseimbangan pada beban.

2. ketidakseimbangan pada sumber listrik (sumber daya).

Kombinasi dari kedua ketidakseimbangan sangatlah rumit untuk mencari pemecahan permasalahannya, oleh karena itu kami hanya akan ketidakseimbangan beban dengan sumber listrik yang seimbang.
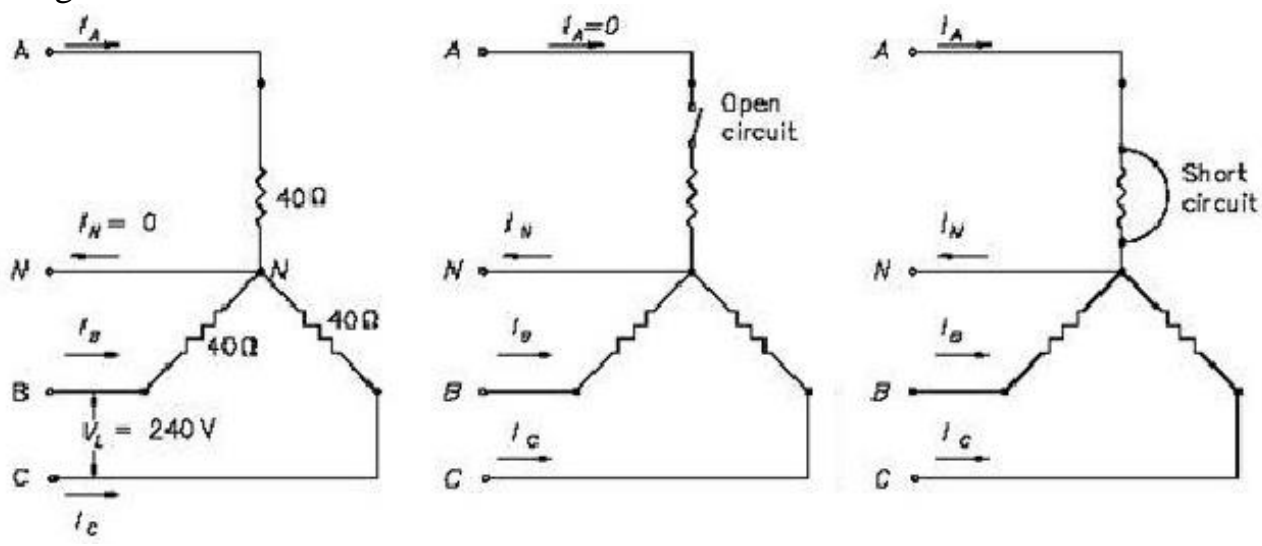

Gambar 2.14. Ketidakseimbangan beban pada sistem 3 fase.

Pada saat terjadi gangguan, saluran netral pada hubungan bintang akan teraliri arus listrik. Ketidakseimbangan beban pada sistem 3 fase dapat diketahui dengan indikasi naiknya arus pada

Analisis Ketidak Seimbangan Beban Transformator Daya 30 MVA 70/20 KV

PT.PLN (Persero) ULTG Lahat

(Surya Darma) 
salahsatu fase dengan tidak wajar, arus pada tiap fase mempunyai perbedaan yang cukup signifikan, hal ini dapat menyebabkan kerusakan pada peralatan.

\section{METODOLOGI PENELITIAN}

\subsection{Tempat dan Waktu Penelitian}

Penelitian dilakukan pada PT.PLN (Persero) ULPT LAHAT tentang Ketidak Seimbangan beban pada Transformator Daya 30 MVA 70/20 KV Garduk Induk Lahat dengan pengamatan serta Analisis selama waktu satu bulan saja.

\section{3,2.Metode Pengumpulan Data}

Metode Pengumpulan Data dilakukan dengan cara sebagai berikut :

1.Metode Observasi langsung Dilapangan tempat objeck penelitian dengan mengadakan pengamatan pada Transformator daya 30 MVA 70/20 KV di PT.PLN (Persero) ULPT LAHAT

2.Studi Literatur yaitu mengumpulkan data-data dari buku Referensi dan jurnal-jurnal yang relevan dengan objectk yang di teliti

3.Wawancara secara langsung dengan stake holder yang ada,tanya jawab pada pegawai pelaksana sebagai pemegang data-data yang akan dibutuhkan sesuai objectk yang akan diteliti di Gardu Induk PT.PLN (Persero) ULPT LAHAT.

\subsection{Pengolahan Data}

1.Perhitungan Arus Beban Penuh Transformator.

2.Ketidak seimbangan Beban.

3.Rugi-Rugi Daya

4.Menentukan Tegangan Titik Netral

\subsection{Analisa Data.[7].[8].[9].}

Setelah tahap pengumpulan Data dan perhitungan ,selanjutnya melakukan analisa data yang akan dikembangkan berdasarkan Literatur yang dipahami dan dipelajari adalah mencari kelayakan ketidak seimbangan beban pada Transformator daya 30 MVA 70?20 KV Gardu Induk ULPT Lahat berdasarkan penelitian pengumpulan data dan hasil Analisa untuk mendapatkan informasi yang harus disimpulkan.

\section{Perhitungan Dan Analisis}

\subsection{Data Transformator 30 MVA 70/20 KV}
a. Daya Nominal
:30 MVA
b. Pabrik
: UNINDO
c. Buatan
: Indonesia
d. Tipe / Model
: TTUB 150/30000
e. Frekuensi
$: 50 \mathrm{~Hz}$

Analisis Ketidak Seimbangan Beban Transformator Daya 30 MVA 70/20 KV

PT.PLN (Persero) ULTG Lahat

(Surya Darma) 
f. TeganganImpedansi

$: 11,42 \%$

g. Type Pendinginan

: ONAN

h. VektorGrup

: YNyn0 / YNd5

i. Tahanan PentanahanTransformator

: $40 \mathrm{Ohm}$

j. TahananTransformator

: $1,8 \mathrm{Ohm}$

\subsection{Hasil Pengeluaran Tegangan Murni}

Tegngan input hasil dari peninjauan voltmeter rata - rata perhari ( per jam )

$\mathrm{V}_{\mathrm{RS}}=20,00 \mathrm{kV}$

$\mathrm{V}_{\mathrm{RT}}=20,03 \mathrm{kV}$

$\mathrm{V}_{\mathrm{ST}}=20,07 \mathrm{kV}$

\section{ArusBeban :}

$\mathrm{I}_{\mathrm{R}}=559 \mathrm{~A}$

$\mathrm{I}_{\mathrm{S}}=564 \mathrm{~A}$

$\mathrm{I}_{\mathrm{T}}=564 \mathrm{~A}$

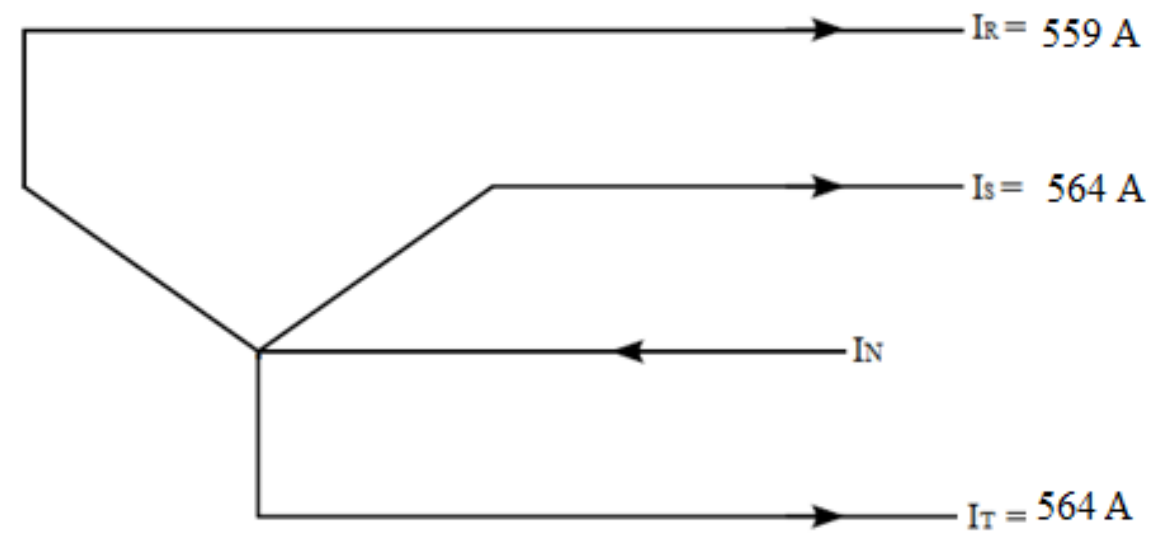

Gambar 4.1. Skema aliran arus listrik pada sisi skunder transformator 30 MVA

\subsection{Perhitungan}

\section{Menentukan Arus Pembebanan Penuh Transformator}

$$
\begin{aligned}
& \text { Daya }: S=30 \text { MVA } \\
& \text { Tegangan } \quad: \mathrm{V}=20 \mathrm{kV} \\
& I_{F L}=\frac{S}{\sqrt{3 \cdot V}} \\
& I_{F L}=\frac{30000 \mathrm{kVA}}{\sqrt{3} .20 \mathrm{kV}} \\
& I_{F L}=866,02 \mathrm{~A}
\end{aligned}
$$

Analisis Ketidak Seimbangan Beban Transformator Daya 30 MVA 70/20 KV PT.PLN (Persero) ULTG Lahat 
Arus rata - rata pengukuran

$\begin{aligned} I_{R T} & =\frac{I_{R}+I_{S}+I_{T}}{3} \\ I_{R T} & =\frac{559+564+564}{3} \\ I_{R T} & =562,33 A\end{aligned}$

\section{Menentukan Persentase Pembebanan Transformator}

$\frac{I_{R T}}{I_{F L}} \times 100 \%$

$\frac{I_{R T}}{I_{F L}}=\frac{562,33 A}{866,025} \times 100 \%$

$\frac{I_{R T}}{I_{F L}}=0,6483 \times 100 \%$

$\frac{I_{R T}}{I_{F L}}=64,93 \%$

\section{Menentukan Persentase Tidak Seimbang}

Untuk transformator 30 MVA menentukan koefisien a, b, dan c

$I_{R}=a \cdot I_{R T}$

Maka :

$$
\begin{aligned}
& a=\frac{I_{R}}{I_{R T}} \\
& a=\frac{559}{561,33} \\
& a=0,9958
\end{aligned}
$$

$I_{S}=b \cdot I_{R T}$

Maka :

$$
\begin{aligned}
b & =\frac{I_{S}}{I_{R T}} \\
b & =\frac{564}{561,33} \\
b & =1,0047
\end{aligned}
$$

$I_{T}=c I_{R T}$

Maka :

$$
\begin{aligned}
& c=\frac{I_{T}}{I_{R T}} \\
& c=\frac{564}{561,33} \\
& c=1,0047
\end{aligned}
$$

Pada keadaan beban seimbang, koefisian a, b, dan c adalah 1. Dengan demikian rata - rata beban tidak seimbang ( dalam \% ) adalah :

Analisis Ketidak Seimbangan Beban Transformator Daya 30 MVA 70/20 KV

PT.PLN (Persero) ULTG Lahat

(Surya Darma) 
Beban tidak seimbang adalah $\quad: \frac{[(a-1)+(b-1)+(c-1)]}{3} \times 100 \%$

$$
: \frac{[(0,995-1)+(1,0047-1)+(1,0047-1)]}{3} \times 100 \%
$$

$$
: 0,16 \%
$$

\subsection{Perhitungan rugi-Rugi Daya.}

1.Menentukan Impedansi Transformator

Impedansi transformator dapat di tentukan dengan persamaan dasar sebagai berikut :

$Z=\frac{V}{I}$

UntukTransformator 30 MVA

Dari data - data yang telah di berikan tegangan perfasa dengan asumsi tegangan fasa seimbang adalah :

$V=\frac{20 \mathrm{kV}}{\sqrt{3}}$

$V=11,544012 k V$

Data transformatorperfasa

$S=\frac{30 M V A}{3}$

$S=10 M V A$

$S=10.000 \mathrm{kVA}$

Arus nominal transformator adalah :

$I_{n}=\frac{S}{V}$

Makadiperoleh :

$I_{n}=\frac{10.000 \mathrm{kVA}}{11,544912 \mathrm{kV}}$

$I_{n}=866,24997 \mathrm{~A}$

Impedansi transformator perfasa adalah :

$Z_{\text {base }}=\frac{\left(k V_{\text {base }}\right)^{2}}{M V A_{\text {base }}}$

$Z_{\text {base }}=\frac{(70)^{2}}{30}$

$Z_{\text {base }}=163,33 \Omega$

Analisis Ketidak Seimbangan Beban Transformator Daya 30 MVA 70/20 KV

PT.PLN (Persero) ULTG Lahat

(Surya Darma) 
$Z_{\text {trafo }}=Z . Z_{\text {base }}$

$Z_{\text {trafo }}=11,42 \% .163,33 \Omega=18,65 \Omega$

$R_{\text {trafo }}=10 \% \cdot Z_{\text {trafo }}=10 \% .18,65 \Omega=1,8 \Omega$

\section{Menentukan Rugi-Rugi Daya.}

Disini di tentukanrugi - rugi daya transformator pada saat beban tidak seimbang.

$$
=I_{0}^{2} \cdot R_{t h}
$$

Dimana :

$$
\begin{aligned}
I_{0}= & \vec{I}_{R}+\vec{I}_{S}+\vec{I}_{T} \text { Didapar sebesar 15,6 } \\
\mathrm{R}_{\mathrm{th}}= & \text { tahanan pentanahan di titik netral terdiri dari tahanan tanah dan tahanan netral sebesar } 40 \\
& +4,5 \Omega=44,5 \Omega .
\end{aligned}
$$

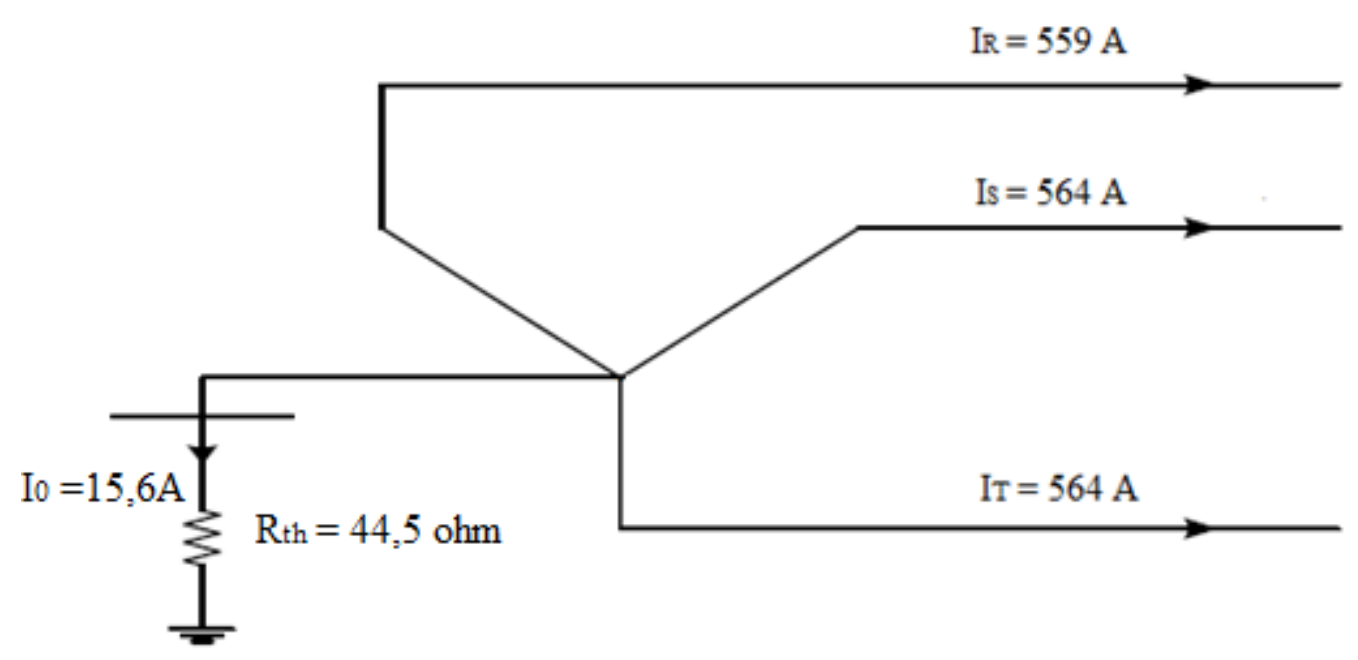

Gambar 4.2. menentukan rugi-rugi daya transformator

Jadi rugi daya akibat ketidak seimbangan beban

$=(15,6)^{2} .44,5 \Omega=10829,5$ watt

Nilai losses inibiladiasumsikan dalam persen adalah :

$=\frac{10829,5}{30 \cdot 10^{6} \cdot 0,8} \times 100 \%=1,50 \%$

\subsection{Perhitungan Tegangan Titik Netral}

Tegangan titik netral terjadi karenaa danya beban yang tidak seimbang pada sistem tiga fasa. Dampak dari ketidak seimbang tersebut menyebabkan bergesernya titik netral.

Pergeseran titik netral ini tergantung dari besar kecilnya arus dari masing - masing fasa. Bilaarus dengan fasa seimbang, maka titik netral tidak akan bergeser.

Analisis Ketidak Seimbangan Beban Transformator Daya 30 MVA 70/20 KV

PT.PLN (Persero) ULTG Lahat

(Surya Darma) 
Pergeseran ini menyebabkan terjadinya tegangan antara titik netral dengan titik pentanahan, sehingga akan timbul arus tanah. Besarnya tegangan antara titik netral dengan titik pentanahan dapat ditentukan dengan menggunakan teganan yang terjadi pada masing - masing fasa, dengan perhitungan secara vektoris yaitu :

$$
\begin{aligned}
\mathrm{V}_{\mathrm{R}} & =20,00 \mathrm{kV} \\
\mathrm{V}_{\mathrm{S}} & =20,03 \mathrm{kV} \\
\mathrm{V}_{\mathrm{T}} & =20,07 \mathrm{kV}
\end{aligned}
$$

Disini di asumsikan bahwa sudut antar fasa seimbang, yaitu sebesar $120^{\circ}$ maka secara viktoris, jumlah tegangan antar fasa adalah :

$V_{R}+V_{T}=\sqrt{\left(V_{R}\right)^{2}+\left(V_{R}\right)^{2}-2 V_{R} V_{T} \cos \theta}$

Makaakan di peroleh :

$V_{R}+V_{T}=\sqrt{(20,00)^{2}+(20,07)^{2}-2(20,00)(20,07) 0,8}$

$V_{R}+V_{T}=\sqrt{400+402,8049-642,24}$

$V_{R}+V_{T}=\sqrt{160604}$

$V_{R}+V_{T}=4.007 \mathrm{kV}=12,67 \mathrm{kV}$

Vector tegangan yang terjadi adalah seperti gambar berikutini :

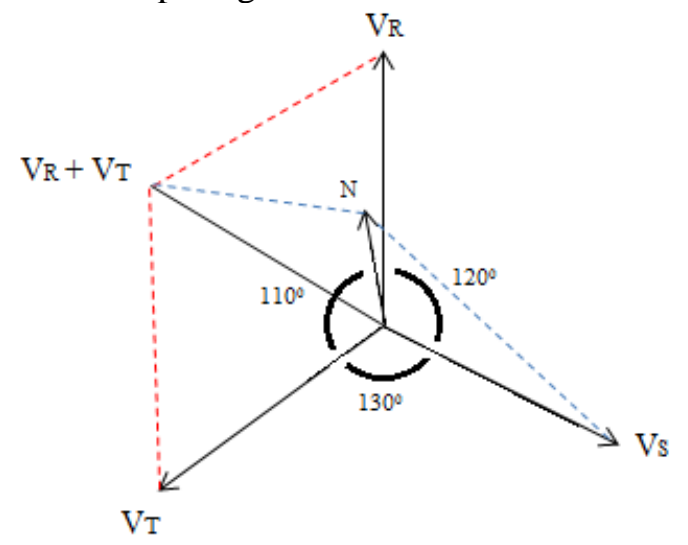

Gambar 4.2. Vector tegangan fasa transformator

Oleh karena tegangan $\left(V_{R}+V_{T}\right)$ dan tegangan $V_{S}$ mempunyai vector yang berlawanan, maka tegangan titik netral dapat di tentukan sebagai berikut :

$\mathrm{V}_{\mathrm{N}}=\left(\mathrm{V}_{\mathrm{R}}+\mathrm{V}_{\mathrm{T}}\right)-\mathrm{V}_{\mathrm{S}} \quad=12,67 \mathrm{kV}-20,0=-7,36 \mathrm{kV}$

\subsection{Analisa}

Dari hasil perhitungan dapat dilihat bahwa, dengan adanya ketidak seimbangan beban pada transformator akan menimbulkan ketidak seimbangan arus, dan akan mengakibatkan rugi - rugi daya u ntuksetiap fasa yang tidak seimbang, yaitu:

Tabel 4.1 Hasil Perhitungan

Transformator 30 MVA

Analisis Ketidak Seimbangan Beban Transformator Daya 30 MVA 70/20 KV

PT.PLN (Persero) ULTG Lahat

(Surya Darma) 


\begin{tabular}{|c|c|}
\hline Arusbebanpenuh & 866,02 A \\
\hline Arus rata - rata & $562,33 \mathrm{~A}$ \\
\hline Persentasepembebanan & $64 \%$ \\
\hline Persentasetidakseimbang & $0,16 \%$ \\
\hline Tegangan ( V ) & $11,54 \mathrm{kV}$ \\
\hline Data transformatorperfasa & $10.000 \mathrm{kVA}$ \\
\hline Arus nominal & 866,24 A \\
\hline Impedansitransformatorperfasa & 13,32 ohm \\
\hline
\end{tabular}

Sumber data Hasil Perhitungan

Dengan terjadinya ketidak seimbangan tersebut, maka akan menimbulkan pergeseran titik netral sebesar-7,36 kV pada transformator 30 MVA. Bila dilihat besarnya tegangan antara $\left(V_{R}+V_{T}\right)$ dan tegangan $V_{S}$. Maka pergeseran titik netral adalah keara hsis itegangan $\left(V_{R}+V_{T}\right)$. di bebani sebesar $64,93 \%$. Sedangkan keadaan tidak seimbnag bebannya adalah $0,1 \%$. Yang berarti transformato rtersebut belum berbeban penuh, tapi sudah mengalami ketidak seimbangan beban. Ketidak seimbangan beban tersebut mengakibatkan ketidak seimbangan arusbeban, sehingga rugi - rugi daya tidak merata yang mengakibatkan terjadinya pergeseran titik netral.

\section{Penutup.}

\subsection{Kesimpulan Dan Saran}

Dari hasil analisa ketidak seimbangan beban pada transformato daya $30 \mathrm{MVA} 70 / 20 \mathrm{kV}$ di Gardu Induk Lahat, didapat perhitungan arus beban penuh $\left(\mathrm{I}_{\mathrm{FL}}\right)$ sebesar 866,02 A,dengan arus rata - rata $\left(\mathrm{I}_{\mathrm{RT}}\right)$ $562,33 \mathrm{~A}$, dan persen tase pembebanan 64,93\%. Untuk persentase koefisien tidak seimbang sebesar $0,16 \%$ dengan rugi - rugi daya akibat keadaan ketidak seimbangan baban ( 0,045 kVA ) Tegangan pada titik netral di peroleh yaitu sebesar-7,36 $\mathrm{kV}$.

\subsection{Saran}

Pada penggunaan transformator 30 MVA di Gardu induk Lahat yang secara langsung mensuplai Energi listrik kekonsumen secara kontinyu memiliki ketidak seimbangan pada fasa R, dan di usahakan agar pembagian beban biasa merata agar tidak ada arus yang mengalir kenetral.

\section{DAFTAR PUSTAKA}

[1]. Dewanto Bagus A.S. 2010. Pengaruh Variasi Pembebanan Terhadap Tegangan Incoming Dan Outgoing Trafo Distribusi $20 \mathrm{kV}$. Tugas Akhir. Jurusan Teknik Elektro Fakultas Teknik Universitas Negeri Malang.

[2],DahlanMoh.ISSN1979-6870. Akibat Ketidakseimbangan Beban Terhadap Arus Netral dan Losses Pada Tranformator Distribusi.FakultasTeknikUniversitas Maria Kudus.

[3]. Kadir Abdul. 1989. Transformator, PT Elex Media Komputindo, Kelompok Gramedia, Jakarta, Indonesia

[4]. MaxtradaBico.2008.Pengaruh Ketidak Seimbangan Beban Antara Fasa- Fasa Menggunakan Transformator Dengan Fasa Netral Terhadap Hasil Pengukuran. Lembaga Penelitian Universitas Indonesia 
[5]. Rabudi,Andri. 2009. Analisa Ketidak Seimbangan Beban Pada Trasnformator Daya 15 MVA di GarduInduk Bukit Siguntang Palembang, Lembaga Penelitian Universitas PGRI Palembang ( TidakDipublikasikan )

[6]. Sumanto. 1991. TeoriTrasformator, Yogyakarta, Indonesia

[7]. SukmadiTejo, 2009. WinardiBambang, Perhitungan Dan Aanalisis Keseimbangan Beban Pada Sistem Distribusi 20 KV Terhadap Rugi-Rugi Daya (STUDI KASUS PADA PT. PLN UPJ SLAWI) Fakultas Teknik, Universitas Diponegoro.

[8] Sibarani David E. 2009.Pengaruh Pemerataan Beban Terhadap Rugi - Rugi Jaringan Tegangan Rendah Transformator Distribusi (AplikasiPada PT. PLN ( Persero ) Rayon Medan kota.FakultasTeknik. Universitas Sumatra Utara Medan.

[9]. LumbanrajaHotdes. 2008.Pengaruh Beban TIdak Seimbang Terhadap Efisiensi Transformator Tiga Fasa Hubungan Open-Delta.FakultasTeknik. Universitas Sumatra Utara Medan. 